\title{
CHARACTERIZATION OF CHILDREN WITH TRUE POSITIVE BLOOD CULTURES IN NORTHERN ISRAEL, 2007-2017: A RETROSPECTIVE STUDY
}

Zaitoon $\mathrm{H}^{1}$, Yaniv $\mathrm{L}^{1}$, Bamberger $\mathrm{E}^{1}$, Mendelson $\mathrm{B}^{2}$, Srugo $\mathrm{I}^{1,2}$, Chistyakov I

${ }^{1}$ Department of Pediatrics, Bnai Zion Medical Center, Haifa, Israel

${ }^{2}$ Clinical Microbiology Laboratory, Bnai Zion Medical Center, Haifa, Israel

Contact information: Hussein.zaitoon@ b-zion.org.il, Phone number: +972-54-9438140

Introduction: Vaccination of children with the conjugated pneumococcal vaccine has reduced the burden of invasive pneumococcal disease in countries where there is widespread use. We characterized the true positive blood cultures (BC) of children aged 3 months to 18 years who presented to a Medical Center in Northern Israel following Prevnar implementation.

Methods: We retrospectively reviewed demographic, clinical and laboratory data of patients with true bacteremia emphasizing age, young group, 3-36 months, and old group, 3 -18 years, and whether there was a focus of infection or bacteremia without focus. Pneumococcal isolates were typed at the National Laboratory for Streptococcus pneumoniae.

Results:

Overall, 909 (2.7\%) of the 34066 samples were with growth, but $562(1.6 \%)$ were deemed contaminants and $246(0.7 \%)$ excluded as patients did not meet inclusion criteria thereby yielding 101 true positive blood cultures for analysis (Figure 1, Table 1)

- Focal infection with concomitant bacteremia was more common than bacteremia alone- overall $73 / 101(72 \%)$ versus $28 / 101(27.7 \%)$, p $<0.001$, in the young group, $34 / 51(66 \%)$ versus $17 / 51(33 \%)$ $\mathrm{p}=0.02$, and old group, $39 / 50(78 \%)$ versus $11 / 50$ $(22 \%), p=0.001$, respectively (Table 2 ).

- Streptococcus pneumoniae was the most common pathogen overall, 29/101 (29\%), and in the young group 22/51 (43\%), but rare in the old group 7/50 (14\%). In the latter, Brucella spp. predominated $13 / 50(26 \%)$ followed by Staphylococcus aureus 12/50 (24\%), (Figure 2, Figure 3).

- In the young group, pneumococcal bacteremia with serotype strains was not uncommon especially in children who were not fully immunized with Prevnar.

- Serotype 19A was the most common non- PCV isolated serotype.

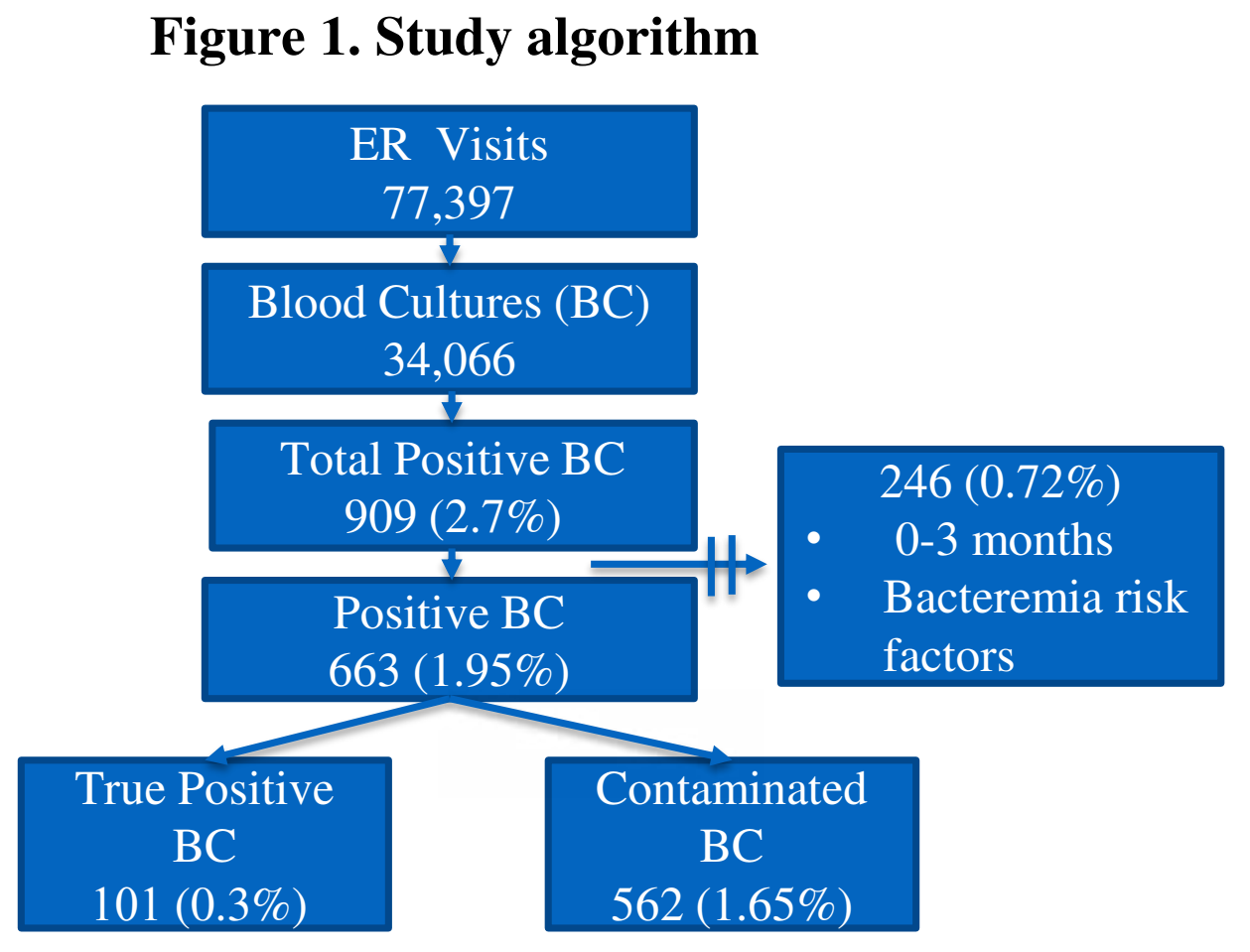

Table 1. Distribution of positive $\mathrm{BC}$ by age

\begin{tabular}{|l|c|c|}
\hline Age & $\begin{array}{l}\text { Total Positive } \\
\text { BC N(\%) }\end{array}$ & $\begin{array}{l}\text { Bacteremia } \\
\mathbf{N}(\%)\end{array}$ \\
\hline $\begin{array}{l}\text { All (\% out of total } \\
\text { samples (34,066)) }\end{array}$ & $663(1.94)$ & $101(0.3)$ \\
\hline 3 months - 3 years & $428(1.25)$ & $51(0.15)$ \\
\hline 3 years - 18 years & $235(0.69)$ & $50(0.15)$ \\
\hline P value & .001 & .92 \\
\hline
\end{tabular}

Table 2. Bacteremia without focus vs. focal infection

\begin{tabular}{|l|c|c|l|l|}
\hline Age & Bacteremia & $\begin{array}{l}\text { Bacteremia } \\
\text { without } \\
\text { focus N(\%) }\end{array}$ & $\begin{array}{l}\text { Focal } \\
\text { infection } \\
\text { N(\%) }\end{array}$ & $\begin{array}{l}\text { P } \\
\text { value }\end{array}$ \\
\hline All & 101 & $28(27.7)$ & $73(72)$ & $<.001$ \\
\hline $\begin{array}{l}\mathbf{3} \text { months - } \\
\text { 3 years }\end{array}$ & 51 & $17(33)$ & $34(66)$ & .02 \\
\hline $\begin{array}{l}\mathbf{3} \text { years- } \\
\mathbf{1 8} \text { years }\end{array}$ & 50 & $11(22)$ & $39(78)$ & .001 \\
\hline
\end{tabular}

Figure 2: Pathogens detected in positive blood cultures overall

$\begin{array}{cc}\begin{array}{c}\text { Kingella kingae } \\ 5 \%\end{array} & \begin{array}{c}\text { Others } \\ 6 \%\end{array} \\ \begin{array}{c}\text { Haemophilus } \\ \text { influenzae } \\ 7 \%\end{array} & \begin{array}{c}\text { Streptococcus } \\ \text { pyogenes } 4 \% \\ \text { pneumoniae } \\ 28 \%\end{array} \\ \begin{array}{c}\text { Escherichia } \\ \text { coli } \\ 11 \%\end{array} & \begin{array}{c}\text { Staphylococcus } \\ \text { aureus } \\ 13 \%\end{array} \\ & \end{array}$

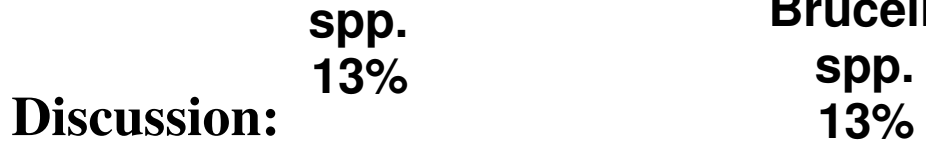

Brucella

- Our study confirms that vaccination with pneumococcal conjugate vaccine greatly reduces the incidence rate of invasive pneumococcal disease, a trend that may justify a new approach to the febrile child in the ED. positive" BC.

- Overall, and in both subgroups, focal infections e.g. pneumonia and UTI more common than children with bacteremia without focus.

- As expected, vaccine pneumococcal serotypes were cultured in partiallyimmunized infants with serotype 19A being the most prominent.

Limitations: The retrospective nature of the study, and its power pose limitations. Moreover, since the study was performed at a single institution, its findings may not generalizable to other pediatric settings. Some blood cultures deemed contaminants, may have been "true

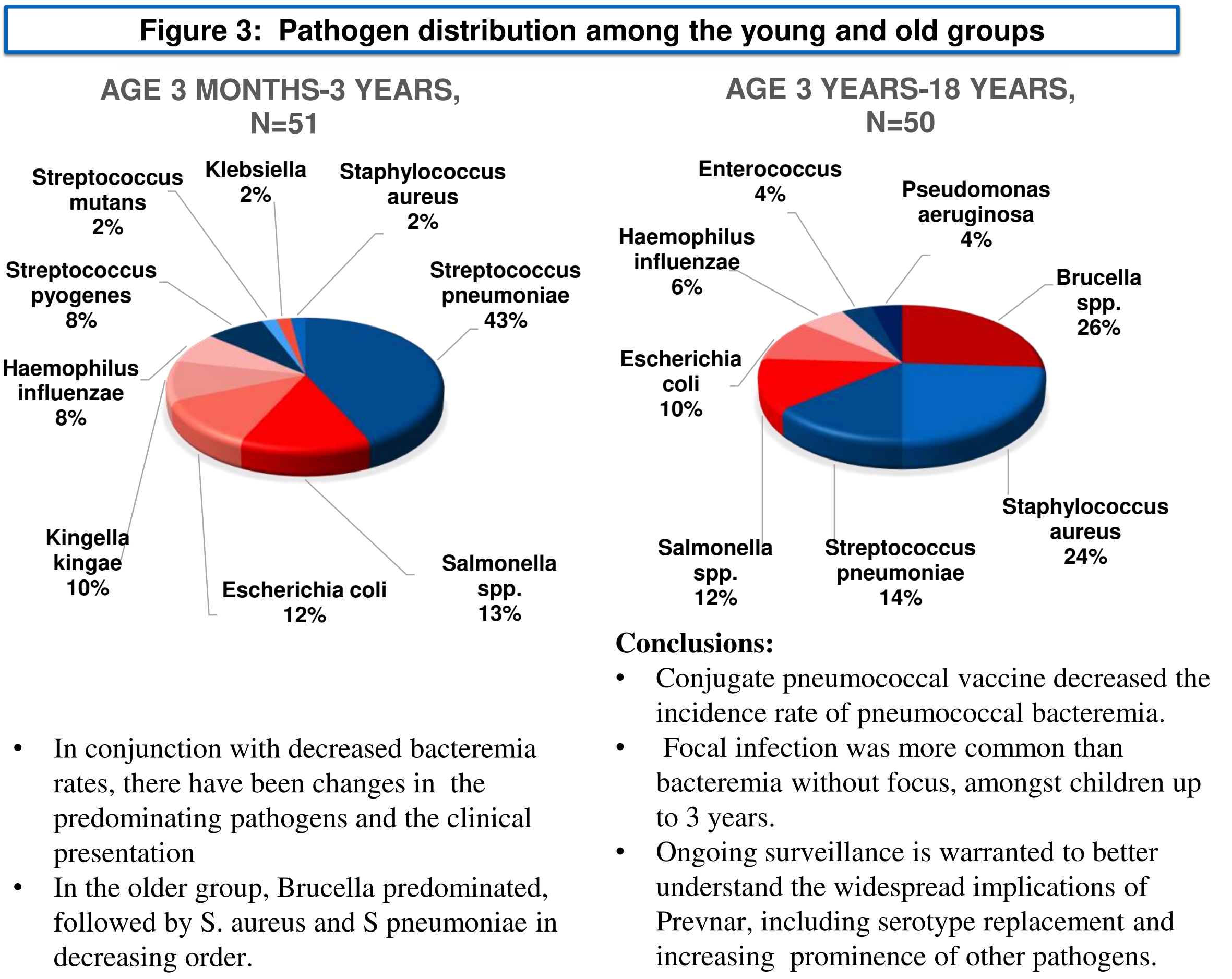

